\title{
Validation of A Point-of-Care Lactate Device For Screening At-Risk Adults Receiving Combination Antiretroviral Therapy In Botswana
}

\section{Citation}

Moyo, Sikhulile, Hermann Bussmann, and Phibeon Mangwendeza, P. Dusara, T Gaolathe, M Mine, R Musonda, E. van Widenfelt, V. Novitsky, J. Makhema, RG Marlink, M Essex, CW Wester. 2011. Validation of A Point-of-Care Lactate Device For Screening At-Risk Adults Receiving Combination Antiretroviral Therapy In Botswana. J Antivir Antiretrovir 3, no. 4. doi:10.4172/ jaa.1000034.

\section{Published Version}

doi:10.4172/jaa.1000034

\section{Permanent link}

http://nrs.harvard.edu/urn-3:HUL.InstRepos:32303182

\section{Terms of Use}

This article was downloaded from Harvard University's DASH repository, and is made available under the terms and conditions applicable to Other Posted Material, as set forth at http:// nrs.harvard.edu/urn-3:HUL.InstRepos:dash.current.terms-of-use\#LAA

\section{Share Your Story}

The Harvard community has made this article openly available. Please share how this access benefits you. Submit a story. 


\title{
Validation of A Point-of-Care Lactate Device For Screening At- Risk Adults Receiving Combination Antiretroviral Therapy In Botswana
}

\author{
Sikhulile Moyo ${ }^{1,{ }^{*}}$, Hermann Bussmann ${ }^{1,2}$, Phibeon Mangwendeza ${ }^{1}$, Priti Dusara ${ }^{1}$, Tendani \\ Gaolathe $^{1}$, Madisa Mine ${ }^{1,3}$, Rosemary Musonda ${ }^{1,2}$, Erik van Widenfelt ${ }^{1}$, Vladimir Novitsky ${ }^{1}$, \\ Joseph Makhema, MBChB ${ }^{1}$, Richard G. Marlink ${ }^{1,2}$, Max Essex $^{1,2}$, and C. William Wester ${ }^{1,4}$ \\ ${ }^{1}$ Botswana-Harvard AIDS Institute Partnership, Gaborone, Botswana \\ ${ }^{2}$ Harvard School of Public Health AIDS Initiative, Department of Immunology and Infectious \\ Diseases, Harvard School of Public Health, Boston, Massachusetts, USA \\ ${ }^{3}$ National Health Laboratory, Gaborone \\ ${ }^{4}$ Vanderbilt University School of Medicine, Vanderbilt Institute for Global Health (VIGH), Nashville, \\ TN, USA
}

\begin{abstract}
Background-Nucleoside reverse-transcriptase inhibitors (NRTIs) are a major component of combination antiretroviral therapy (cART) worldwide but they have been associated with mitochondrial toxicities, with one of the most significant being lactic acidosis. In southern Africa, being female and overweight (BMI > 25) as well as receiving $\mathrm{d} 4 \mathrm{~T}$ and/or ddI-based cART are risk factors for the development of this potentially life-threatening complication. It is challenging in many resource-limited settings to obtain reliable serum lactate measurements while screening for the presence of lactic acidosis. Point-of-care devices, however, are now available that provide simple, accurate measurements of serum lactate levels at relatively low cost. The objective of this study was to assess the agreement of the portable (Accutrend ${ }^{\mathrm{TM}}$ handheld) lactate analyzer to the conventional laboratory system for obtaining serum lactate.
\end{abstract}

Methods-Eighty two "at-risk" cART-treated adults were evaluated, having their lactate levels tested in parallel using both modalities.

Results-The mean (range) lactate level for the portable device was 2.28 (0.9-5.0) compared to 1.96 (0.7-5.4) using the conventional method. There was a strong correlation ( $\mathrm{p}<0.05)$ between the portable device and the conventional means with a Pearson correlation coefficient of 0.92 [95\% CI: 0.88-0.95]. The mean bias was 0.33 [95\% CI: -0.39-1.04], with the portable device having slightly higher values.

Conclusion-The use of a portable lactate device provides an accurate and user-friendly means of screening at-risk patients for the presence of lactic acidosis in resource-limited settings with limited laboratory capacity.

Copyright: (C) 2011 Moyo S, et al.

"Corresponding author: Sikhulile Moyo, Botswana-Harvard AIDS Institute Partnership, P/Bag BO 320 Gaborone, Botswana, Tel: +267 3902671; Fax: +267 3901284; smoyo@bhp.org.bw.

Publisher's Disclaimer: This is an open-access article distributed under the terms of the Creative Commons Attribution License, which permits unrestricted use, distribution, and reproduction in any medium, provided the original author and source are credited 


\section{Keywords}

HIV/AIDS; lactic acidosis; Botswana; Point-of-care devices; Complications of combination antiretroviral therapy (cART)

\section{Introduction}

Although nucleoside reverse-transcriptase inhibitors (NRTIs) remain a critical component of current HIV-1 treatment regimens, they have been associated with functional and structural mitochondrial abnormalities, leading to several adverse events, such as pancreatitis, peripheral neuropathy, and lactic acidosis [1-7]. Moderate-severe symptomatic hyperlactatemia and lactic acidosis are potentially life threatening and complicate the use of NRTIs [1,3,4]. Rates of lactic acidosis appear to be higher in southern Africa, 1.1-1.2\%, $[1,3,8-10]$ when compared with rates previously described elsewhere, $0.1-0.4 \%[4,9]$. The development of lactic acidosis is one of the most serious mitochondrial toxicities with published case fatality rates of up to $80 \%$ among patients with lactate levels $>10 \mathrm{mmol} / \mathrm{L}$ [11]. Risk factors for the development of moderate to severe symptomatic hyperlactatemia or lactic acidosis include female gender, use of "D" antiretroviral drugs (didanosine (ddI) and/or stavudine (d4T)), having a BMI of greater than 25 , decreased $\mathrm{CD}^{4+}$ cell count, the presence of lipodystrophy, and having elevated plasma triglyceride levels [9,12]. Additional studies are ongoing to evaluate for other possible risk factors, such as host genetic factors. WHO also recommends that countries phase out the use of d4T, because of its long-term, irreversible side-effects [13]. Stavudine is still widely used in first-line therapy in developing countries due to its low cost and widespread availability, and programmatic implications of moving towards alternative more costly drugs still need to be sorted out. Lactate measurements will continue to be necessary in many poor resource settings. It is challenging in many resource-limited settings to obtain reliable serum lactate measurements while screening for the presence of lactic acidosis, which often manifests in subtle fashion (i.e. nausea, vomiting, abdominal pain, fatigue, etc.) among persons experiencing this complication $[14,15]$.

Lactate measurements are presently obtained on cART-treated persons having one or more clinical signs and symptoms that may be predictive of lactic acidosis, namely the presence of new nausea/emesis, unexplained fatigue, shortness of breath, abdominal pains, and/or unexplained weight loss. Conventional lactate measurements have to be drawn in specific fashion, namely no tourniquet is to be used and ideally patients should not have vigorously exercised or drank alcohol within the 6-12 hours before blood draw. In addition, lactate levels need to be drawn in sodium fluoride tubes and these tubes need to be maintained on ice with the tubes being transported to the lab within 15 minutes for optimal lactate testing. In addition, to confirm the diagnosis of lactic acidosis, some assessment of the person's acid-base status is needed which is typically done via serum bicarbonate $\left(\mathrm{HCO}_{3}\right)$ and/or venous or arterial $\mathrm{pH}$ measurements. This is logistically very challenging, especially in busy outpatient HIV clinics where hundreds of patients are being seen per day and where proximity to the central laboratory may be an issue. Point-of-care (POC) devices are now available that provide simple, accurate measurements of serum lactate levels at relatively low cost [16]. Their use in HIV treatment programs and intensive care medicine has greatly assisted clinical decision-making in patients with symptoms suggestive of lactic acidosis in other settings [17-21], but have never been validated in our setting. In this study, we formally validated one POC lactate device (made by Roche ${ }^{\mathrm{TM}}$ ) for use in our setting. 


\section{Methods}

\section{Study population}

cART-treated adults from 2 settings in Gaborone, Botswana were screened for enrollment into this one-visit cross-sectional study: (i) adult cART-treated patients currently enrolled in the Adult Antiretroviral Treatment and Drug Resistance ("Tshepo") study [22] and (ii) HIV-1 infected adult patients receiving longitudinal care at the adult Infectious Disease Care Clinic (IDCC) on the grounds of Princess Marina Hospital; the vast majority of which are receiving cART. Enrollment took place during August-November 2007. In terms of clinical condition, the goal was to enroll 20-25\% symptomatic patients, with "symptomatic" being defined as having one or more of the following symptoms and/or laboratory abnormalities suggestive of underlying lactic acidosis: grade 3 or higher SGPT and/or SGOT, grade 3 or higher LDH; nausea/emesis, increased fatigue, dyspnea, muscle weakness, and/or paralysis of the lower extremities and/or having a serum bicarbonate level less than $20.0 \mathrm{mmol} / \mathrm{L}$.

\section{Laboratory procedures}

One blood specimen ( 3.0 mLs) was collected using venupuncture, with no tourniquet, from each consenting study participant. From this specimen lactate was measured via 2 means: (i) $\sim 50 \mu 1$ was directly placed onto a lactate strip which was then (per manufacturer's instructions) placed in the Roche POC lactate device, Accutrend (Roche Diagnostics GmbH, Mannheim Germany) and the result was recorded in our study case report forms (CRFs) (without patient name/initials to protect confidentiality); and (ii) 2.5-2.9 mLs was placed immediately into a grey top specimen tube on ice which was immediately (within 15 minutes of blood draw) transported to the central Botswana-Harvard HIV Reference Laboratory (BHHRL) on the grounds of Princess Marina Hospital in Gaborone for conventional lactate testing using the Roche Integra 400 Plus $^{\mathrm{TM}}$ (Roche Diagnostics, Mannheim, Germany) as per manufacturer's instructions. The results were compared to the results obtained via the portable device with all results being anonymously recorded in our study case report forms. BHHRL operates under GCLP and with an ISO17025 based clinical laboratory quality management system.

\section{Statistical considerations}

The necessary sample size for the comparison of the portable lactate device and the gold standard (conventional) diagnostic test was derived based on a known standard deviation of $0.1 \mathrm{mmol} / \mathrm{L}$ and $90 \%$ power aimed to have the ability to detect a difference of $0.05 \mathrm{mmol} / \mathrm{L}$ between the two methods, and therefore a significance level of 5\%, the study required a sample size of 35 participants in each method. Mean standard deviations were calculated for all lactate results obtained in parallel via these two testing methods, namely "conventional gold standard (grey top on ice)" versus "portable POC lactate device". The bias (mean difference between the 2 methods) and limits of agreement of the 2 test methods was analyzed using the method described by Bland and Altman [23]. The upper and lower limits of agreement were calculated as bias \pm 2 standard deviations. Accuracy (mean bias) and the relative error ((conventional lactate - portable lactate)/(conventional lactate + portable lactate)) were also calculated [24]. Correlation analysis (Pearson) was used to describe the strength of the relationship between the two methods. P values of $<0.05$ were considered significant. A total allowable error (TEa) of $20 \%$ was adopted [25].

The study was approved by the Botswana Ministry of Health's Health and Research Development Committee (HRDC), and the Human Subjects Committee (Harvard School of Public Health). 


\section{Results}

Eight-two (82) patients had serum lactate results performed in parallel (portable POC versus conventional). Patient characteristics are shown in (Table 1). Seventy-seven percent (77\%) were female, $100 \%$ were black/of Tswana origin; their median age was 36 years (range 23-53 years); the majority were receiving zidovudine (ZDV), lamuvidine (3TC) (coformulated as Combivir ${ }^{\mathrm{TM}}$ ) plus nevirapine (NVP) (27\%) or zidovudine (ZDV), lamuvidine (3TC), plus efavirenz (EFV) (26\%). Eighteen percent (18\%) of the patients were "symptomatic'; in that they had symptoms and/or laboratory abnormalities suggestive of possible underlying lactic acidosis.

The mean (range) lactate level from the portable lactate (portlac) was $2.28 \mathrm{mmol} / \mathrm{L}(0.9-5.0)$ and 1.96 (0.7-5.4) using the conventional method (convlac). There was a strong correlation $(\mathrm{p}<0.05)$ between conventional laboratory lactate (convlact) and the portable point of care lactate (portlact) with a Pearson correlation coefficient of 0.92 [95\% CI: 0.88-0.95]. Method correlation by least squares regression (using convlact as the reference) yielded a slope of 1.2 , an intercept of -0.74 , and an adjusted $\mathrm{r}^{2}$ of 0.85 . Passing-Bablok regression [26] yielded a slope of 0.77 and intercept of 0.85 (Figure 1). Bland-Altman [23] plots shown in Figure 2 indicated a mean bias of 0.33 (95\% CI $0.25-0.41)$, with portable lactate having slightly higher values than conventional lactate but within $20 \%$ acceptable total allowable error for absolute differences [25]. The 95\% confidence intervals for the limits of agreement were -0.39 to 1.04 .

\section{Discussion}

Excellent overall immunologic, virologic, clinical response rates and adherence rates have been reported from numerous adult antiretroviral treatment cohorts in sub-Saharan Africa $[27,28]$ (at least comparable to that observed in the West). The majority of HIV-1 infected cART-treated adults in Africa are receiving d4T-based first-line regimens [13,29]. Reasons for this are primarily financial. Regional data has shown that cART-treated adults in southern Africa have higher than expected rates of mitochondrial toxicities, i.e. pancreatitis and lactic acidosis, which may be life-threatening. Risk factors for the development of lactic acidosis include being female $(\mathrm{p}=0.008)$ and being overweight $(\mathrm{BMI}>25 ; \mathrm{p}=0.001)$ [9].

Lactate measurements are often not routinely available in many resource-limited settings due to limited laboratory infrastructure. In addition, conventional serum lactate measurements have to be drawn in specific fashion, namely no tourniquet is to be used and ideally patients should not have vigorously exercised or drank alcohol within 6-12 hours prior to their blood draw. In addition, serum lactate levels need to be drawn in sodium fluoride tubes and these tubes need to be maintained on ice with the tubes being transported to the lab within 15 minutes for optimal lactate testing. This can be challenging in many poor resource or remote settings. The use of the now available point-of-care devices in HIV treatment programs can greatly assist clinical decision-making in patients with symptoms suggestive of lactic acidosis. This has been shown to be effective in other programs elsewhere and intensive care medicine [17-21] at relatively low cost [16].

The portable lactate device produced comparable results in our setting. Although the portable lactate had a positive bias of 0.33 , it was not clinically significant and there was a significant positive correlation between the two methods similar to what has been previously published [16,30]. Additional advantages of this portable POC technology is that the devices are simple to operate and work in identical fashion to the diabetic portable devices used to reliably monitor blood glucose levels among diabetic patients. Portable lactate can potentially be used in resource limited settings as is provides other advantages such short 
turn-around time (1-2 minutes), eliminating the need for special tubes, transportation of specimens on ice and restricted time before testing in a routine laboratory. Some technologies have now been developed with battery of tests such as lactate, glucose and triglycerides and this can improve the clinician's management of patients. This POC testing modality is also considerably more affordable when compared to conventional lactate testing as the POC device costs 1200 South African Rand (ZAR), (approximately USD 160.00) and reagent strips cost only $\sim 9$ ZAR each (approximately USD 1.30) compared to reagent costs/test of approximately ZAR 80 (approx USD 11.00) for the for the conventional test. Laboratory equipment required for the conventional test includes a dedicated power supply, maintenance and laboratory expertise to operate. One of the limitations of this study is that we could not validate the point of care machine for lactate results of more than $5.4 \mathrm{mmol} / \mathrm{l}$. However significant lactic acidosis is present if the blood lactate concentration is $>5.0$ $\mathrm{mmol} / \mathrm{L}$.

\section{Conclusion}

The use of a portable lactate device provides an accurate and user friendly means of screening at-risk patients for the presence of lactic acidosis. Such a device should be considered for screening atrisk patients being cared for in resource-limited settings with limited laboratory capacity.

\section{Acknowledgments}

We want to formally acknowledge and thank all adult study participants. We would like to formally acknowledge the Botswana Ministry of Health, the Botswana-Harvard HIV Reference Laboratory (BHHRL), the Princess Marina Hospital administration, outpatient adult Infectious Disease Care Clinic (IDCC), and inpatient Medical Ward teams, the entire Adult Antiretroviral Treatment and Drug Resistance (Tshepo) study team and our funder, the BristolMyers Squibb foundation for their support of this research initiative. The project described was also supported by the following research grants from the National Institute of Allergy and Infectious Diseases, K23AI073141 (PI: C. William Wester, MD, MPH) and P30AI 060354 (PI: C. William Wester, MD, MPH) Harvard Center for AIDS Research (CFAR) grants. The content is solely the responsibility of the authors and does not necessarily represent the official views of the National Institute of Allergy and Infectious Diseases or the National Institutes of Health.

Lastly, we would like to thank Danae Roumis and Allison Tripp (Administration, Harvard School of Public Health, Boston, MA, USA) for their assistance with this manuscript.

\section{References}

1. Osler M, Stead D, Rebe K, Meintjes G, Boulle A. Risk factors for and clinical characteristics of severe hyperlactataemia in patients receiving antiretroviral therapy: a case-control study. HIV Med. 2010; 11:121-129. [PubMed: 19702629]

2. Bussmann H, Wester CW, Ndwapi N, Grundmann N, Gaolathe T, et al. Five-year outcomes of initial patients treated in Botswana's National Antiretroviral Treatment Program. AIDS. 2008; 22:2303-2311. [PubMed: 18981769]

3. Stead D, Osler M, Boulle A, Rebe K, Meintjes G. Severe hyperlactataemia complicating stavudine first-line antiretroviral therapy in South Africa. Antivir Ther. 2008; 13:937-943. [PubMed: 19043928]

4. Lactic-Acidosis-International-Study-Group. Risk factors for lactic acidosis and severe hyperlactataemia in HIV-1-infected adults exposed to antiretroviral therapy. AIDS. 2007; $21: 2455-$ 2464. [PubMed: 18025882]

5. Calza L, Manfredi R, Chiodo F. Hyperlactataemia and lactic acidosis in HIV-infected patients receiving antiretroviral therapy. Clinical Nutrition. 2005; 24:5-15. [PubMed: 15681097]

6. Brinkman K, Smeitink JA, Romijn JA, Reiss P. Mitochondrial toxicity induced by nucleosideanalogue reverse-transcriptase inhibitors is a key factor in the pathogenesis of antiretroviraltherapy-related lipodystrophy. Lancet. 1999; 354:1112-1115. [PubMed: 10509516] 
7. Koczor CA, Lewis W. Nucleoside reverse transcriptase inhibitor toxicity and mitochondrial DNA. Expert Opin Drug Metab Toxicol. 2010

8. Wester CW, Thomas AM, Bussmann H, Moyo S, Makhema JM, et al. Non-nucleoside reverse transcriptase inhibitor outcomes among combination antiretroviral therapy-treated adults in Botswana. AIDS. 2010; 24(1):7-36.

9. Wester CW, Okezie OA, Thomas AM, Bussmann H, Moyo S, et al. Higher-than-expected rates of lactic acidosis among highly active antiretroviral therapy-treated women in Botswana: preliminary results from a large randomized clinical trial. J Acquir Immune Defic Syndr. 2007; 46:318-322. [PubMed: 18090299]

10. Bolhaar MG, Karstaedt AS. A high incidence of lactic acidosis and symptomatic hyperlactatemia in women receiving highly active antiretroviral therapy in Soweto, South Africa. Clin Infect Dis. 2007; 45:254-260. [PubMed: 17578788]

11. Falco V, Rodriguez D, Ribera E, Martinez E, Miro JM, et al. Severe nucleoside-associated lactic acidosis in human immunodeficiency virus-infected patients: report of 12 cases and review of the literature. Clin Infect Dis. 2002; 34:838-846. [PubMed: 11850865]

12. Bonnet F, Balestre E, Bernardin E, Pellegrin JL, Neau D, et al. Risk factors for hyperlactataemia in HIV-infected patients, Aquitaine Cohort, 1999--2003. Antiviral Chemistry and Chemotherapy. 2005; 16:63-67. [PubMed: 15739622]

13. WHO. Antiretroviral therapy for HIV infection in adults and adolescents: recommendations for a public health approach. Geneva, Switzerland: WHO Press, World Health Organization; 2010. 2010 revision

14. Carr A. Lactic acidemia in infection with human immunodeficiency virus. Clin Infect Dis. 2003; 36:S96-S100. [PubMed: 12652378]

15. Claessens YE, Cariou A, Monchi M, Soufir L, Azoulay E, et al. Detecting life-threatening lactic acidosis related to nucleoside-analog treatment of human immunodeficiency virus-infected patients, and treatment with L-carnitine. Critical Care Medicine. 2003; 31:1042-1047. [PubMed: 12682470]

16. Kiragga AK, Ocama P, Reynolds SJ, Kambugu A, Ojiambo H, et al. Validation of a portable handheld lactate analyzer for determination of blood lactate in patients on antiretroviral therapy in Uganda. J Acquir Immune Defic Syndr. 2008; 49:564-566. [PubMed: 19202460]

17. Moore CC, Jacob ST, Pinkerton R, Meya DB, Mayanja-Kizza H, et al. Point-of-care lactate testing predicts mortality of severe sepsis in a predominantly HIV type 1-infected patient population in Uganda. Clin Infect Dis. 2008; 46:215-222. [PubMed: 18171253]

18. Ivers LC, Mukherjee JS. Point of care testing for antiretroviral therapy-related lactic acidosis in resource-poor settings. AIDS. 2006; 20:779-780. [PubMed: 16514312]

19. van Griensven J, Atte EF, Reid T. Symptomatic hyperlactatemia: lessons learned using a point-ofcare device in a health care center- and nurse-based antiretroviral program in Rwanda. Clin Infect Dis. 2008; 46:320-322. [PubMed: 18171270]

20. Boldt J, Kumle B, Suttner S, Haisch G. Point-of-care (POC) testing of lactate in the intensive care patient. Accuracy, reliability, and costs of different measurement systems. Acta Anaesthesiologica Scandinavica. 2001; 45:194-199. [PubMed: 11167165]

21. Brinkert W, Rommes JH, Bakker J. Lactate measurements in critically ill patients with a hand-held analyser. Intensive Care Medicine. 1999; 25:966-969. [PubMed: 10501753]

22. Bussmann H, Wester CW, Thomas A, Novitsky V, Okezie R, et al. Response to zidovudine/ didanosine-containing combination antiretroviral therapy among HIV-1 subtype C-infected adults in Botswana: two-year outcomes from a randomized clinical trial. J Acquir Immune Defic Syndr. 2009; 51:37-46. [PubMed: 19282782]

23. Bland JM, Altman DG. Statistical methods for assessing agreement between two methods of clinical measurement. Lancet. 1986; 1:307-310. [PubMed: 2868172]

24. Mantha S, Roizen MF, Fleisher LA, Thisted R, Foss J. Comparing methods of clinical measurement: reporting standards for bland and altman analysis. Anesthesia and Analgesia. 2000; 90:593-602. [PubMed: 10702443]

25. DigitalPTAccuTest. PT Evaluation Criteria - CMS/Collaboration. Westford, MA: DigitalPT; 2010. 
26. Passing H, Bablok. A new biometrical procedure for testing the equality of measurements from two different analytical methods. Application of linear regression procedures for method comparison studies in clinical chemistry, Part I. Journal of Clinical Chemistry and Clinical Biochemistry. 1983; 21:709-720.

27. Bussmann H, Wester CW, Thomas A, Novitsky V, Okezie R, et al. Response to Zidovudine/ Didanosine-Containing Combination Antiretroviral Therapy Among HIV-1 Subtype C-Infected Adults in Botswana: Two-Year Outcomes from a Randomized Clinical Trial. JAIDS Journal of Acquired Immune Deficiency Syndromes. 2009; 51:37-46.

28. Wester CW, Bussmann H, Koethe J, Moffat C, Vermund S, et al. Adult combination antiretroviral therapy in sub-Saharan Africa: lessons from Botswana and future challenges. HIV Therapy. 2009; 3:501-526. [PubMed: 20161344]

29. Colebunders R, Kamya MR, Laurence J, Kambugu A, Byakwaga H, et al. First-line antiretroviral therapy in Africa--how evidence-base are our recommendations? AIDS Rev. 2005; 7:148-154. [PubMed: 16302462]

30. Karon BS, Scott R, Burritt MF, Santrach PJ. Comparison of lactate values between point-of-care and central laboratory analyzers. American Journal of Clinical Pathology. 2007; 128:168-171. [PubMed: 17580286] 


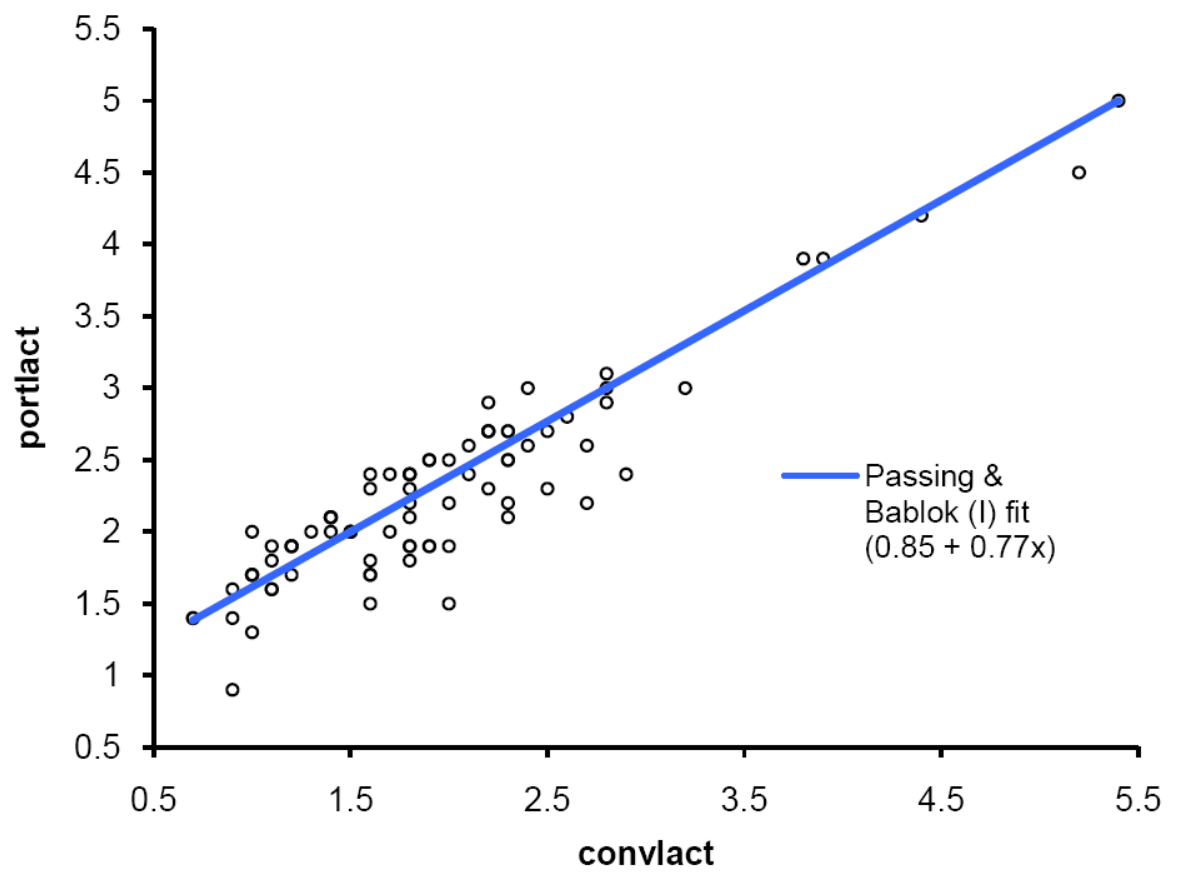

Figure 1.

Scatter plot with Passing-Bablok regression fit for portable point of care lactate (portlact) versus conventional laboratory lactate (convlact). 


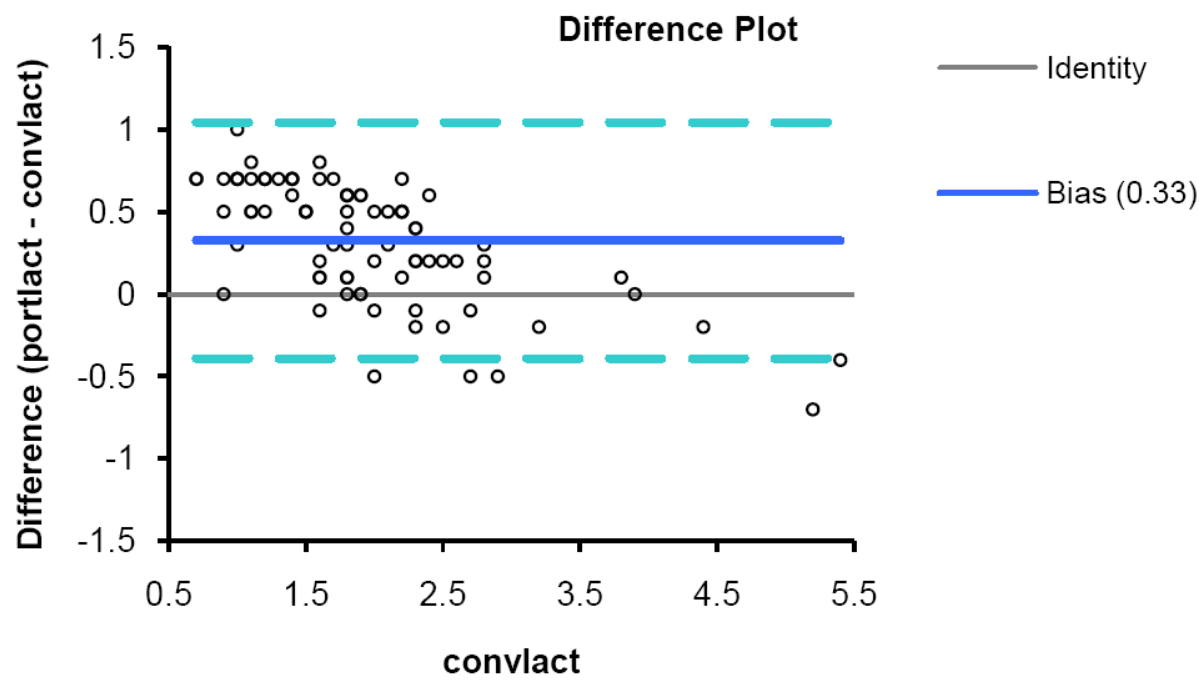

Figure 2.

Difference plot for portable lactate (portlact) versus conventional laboratory lactate (convlact). 
Table 1

Baseline characteristics of study population.

\begin{tabular}{|l|l|l|}
\hline \multicolumn{2}{|l|}{ Demographic and clinical characteristics of study participants } \\
\hline Gender & Male & $19(23 \%)$ \\
\hline & Female & $63(77 \%)$ \\
\hline Age (years) & Mean (Std Dev) & $36.6(+/-7.4)$ \\
\hline & Median (Range) & $36(23-53)$ \\
\hline Clinical presentation & Symptomatic & $15(18 \%)$ \\
\hline & Asymptomatic & $67(82 \%)$ \\
\hline & & \\
\hline cART Regimen & CBV/NVP & $22(27 \%)$ \\
\hline & CBV/EFV & $21(26 \%)$ \\
\hline & d4T/3TC/NVP & $10(12 \%)$ \\
\hline & d4T/3TC/EFV & $7(9 \%)$ \\
\hline & Other & $22(27 \%)$ \\
\hline &
\end{tabular}

Abbreviations: CBV: Combivir ${ }^{\mathrm{TM}}$ (co-formulated zidovudine (ZDV) plus lamuvidine (3TC)); NVP: nevirapine; EFV: efavirenz; d4T: stavudine; 3TC: lamuvidine 